\title{
The Hydrodynamics of a Bleaching Event: Implications for Management and Monitoring
}

\author{
William Skirving, Mal Heron and Scott Heron
}

\begin{abstract}
This chapter examines the hydrodynamic conditions that are present during a coral blenching event. Meteorological and climate parameters and influences are discussed. The physics of mixing and its influence on the horizontal and vertical variations of sea temperature are examined. A specialized hydrodynamic model for Palau is then presented as a case study to demonstrate the utility of these models for understanding spatial variation during bleaching events. This case study along with the other sections of this chapter pro vide the foundation for concluding that hydrodynamic modeling can provide us with a relatively accurate glimpse of the spatial variation of thermal stress and, therefore, what future stress events may hold for corals. Although the timing of a coral bleaching event is unknown and cannot be predicted with current technology, the relative patterns of sea surface temperature during individual bleaching events can be predicted using current modeling techniques. However, improvements in our understanding of coral physiology and higher spatial-resolution climate models are necessary before the full potential of these predictions can be utilized in management decisions.
\end{abstract}

\section{Introduction}

Coral bleaching is a generalized stress response by the coral-zooxanthellae symbiosis and is not necessarily related to any one stressor [Glynn, 1993]. To date, mass coral bleaching events have been correlated with thermal stress [e.g., Dennis and Wicklund, 1993; Drollet et al., 1994; Winter et al., 1998; Hoegh-Guldberg, 1999; McField, 1999; Berkelmans, 2002]. The physiological mechanism is that high temperatures damage the photosynthetic pathway, which leads to a breakdown of the photosynthetic process [Jones et al., 1998]. After the thermal threshold is surpassed, the normally robust photo system can be overwhelmed by significant amounts of light, eventually causing the formation of reactive oxygen molecules that eventually destabilizes the relationship between corals and their symbionts [Hoegh-Guldberg, 1999; Downs et al., 2002]. Therefore, although light is an important factor in the coral bleaching story, it is not normally a stressor until water temperatures have exceeded certain limits [Berkelmans, 2002].

Coral Reefs and Climate Change: Science and Management

Coastal and Estuarine Studies 6

Copyriglt 2006 by the American Geophysical Union.

10.1029/61CE09 
At present, coral bleaching conditions are monitored in near real-time using satcllitebased Advanced Very High Resolution Radioneter data. 'The U.S. National Oceanic and Atmospheric Administration (NOAA) Coral Reef Watch (CRW) program produces halfweekly, $50 \mathrm{~km}$ resolution sca surface temperalure (SST) and varjous derivative products with global coverage (see htp:/conalreefwatch.noaa.gov). These prodicts provide reef managers and stakcholders with up-to-date information on their jurisdiction. However, physical characteristics of a reef-site that can enhance or mitigate thermal stress are identifiable and, as such, can be used to provide managers with a niny defining which regions are more susceptible to thermal stress. This chapter will investigate the origin and spatial variation of the warm water that is known to be a major factor in coral bleaching.

Mass Coral Bleaching: Climate or Weather?

\section{Links between El Niño and Bleaching}

There is much talk about El Niño being the "cause" of the 1998 coral bleaching event. If this link exists then we would expect a correlation between EJ Nino and bleaching around the world. Arzayus and Skirving [2004] took the CRW satellite-derived Degree Heating Week (DHW) product and using the suggested value of $\mathrm{DHW}=4$ to indicate bleaching, they hindcast bleaching conditions back to 1985 for the entire world. A contparison was then made between the hindcast bleaching conditions and EI Niño, La Ninta and Neutral states (here referred as ENSO states) as defined by the National Centers for Environmental Prediction's Oceanic Niño Index. (ht1p:/www.cpe.nona.gov/products/ antalysis_monitoring/ensostuf(ensoyears.shtml)

Arzayus and Skirving [2004] defined that a $50 \mathrm{~km}$-square region is correlalcid with am ENSO state if $70 \%$ or more of bleaching events ofcur during that ENSO state. They found that only $0.2 \%$ of bleaching events on reefs are correlated will an ENSO state $(0.05 \%$ with El Niño. 0. L 4\% witl La Niña. and 0.0 ! \% whth Neutral conditions. Althougl the effects of different ENSO states on bleaching severity were not examined, it whs clearly shown that the onset of bleaching is not correlated with ENSO for the vast majority of world reefs. In fact, the variability of local weather conclitions is greater than the climatological mearıs which are used to characterize ENSO stites.

\section{Bleaching Weather}

Skirving and Guinotte $[200 /]$ investigated the origin of the warm water that calused parts of the Great Barrice Reef (GBR) to bleacl during 1998. They noted llat a combination of low wind speed alnd netp tides was correlated with high SST. They also noted that during these warm periods there was another correlation between shallow bathymetry and relatively cooler SST.

These correlations led then to conclude that the warn watel was a result of local heating from solar radiation in conditions where there was a lack of hydrodymamic mixing. The idca that SST anomalies leading to coral bleaching are mostly a result of local heating has since been supported by many field observations [Wilkinson, 199S: Wilkiuson, 2000: Berkelmans et al., 2004; Bird et al., 2004; Skirving el al., 2004].

Very few mass coral blenching events in the world are a result of advected warm water [Skirving, 2004]. Litsle to no wind, clear sumny skies and weak ocean currents characlerize these events and. as such, local beating is the cause of almost all thermally-indwect 
mass coral bleaching events. It would therefore be more accurate to describe mass corat bleaching as a weather phenomenon rather than the result of climate, as is currently popular. Climate is likely 10 modulate the frequency and intensity of these weather events, but more researcli is necessary beforc direct links between cliniate states [e.g., El Niño] and coral bleaching can be understond.

\section{El Niño and Weather: A GBR Case Study}

The record 1998 GBR bleaching event occurted during the intense 1998 El Niño event and. as a result, many scientists and managers believed that El Niño may be a key component to significant blesching events on the GBR.

The 2002 cotal bleaching event in the GBR was more significant than the 1998 bleaching event in every measurable aspect; SSTs were genernily higher, bleaching was more extensive and there was higher mortality [Wilkinson, 2002]. The puzzling thing was that the EJ Niño did not begin unil a number of montbs after the GBR blenched. This cast doubt on the causal link betwesı El Niño and GBR bleaching events.

In 2003, the Conal Reef Watch team within NOAA/NESDIS used their DHW and HolSpot satellite products to examine the intensity and accumulated hent stress for the GBR during both bleacling events [Liu ct al., 2003]. They noticed that each bleaching event was accompanied by a significant pool of anomalously wam water that covered thousands of square kilometers. The kcy difference between the 1998 and 2002 blenching events was not in the intensity of the SST anomaly that catised each cvent, but in the proximity of the anomaly to the GBR [Liu et al.. 2003]. The fact that the 1998 bleaching occurred during a strong El Niño, while the 2002 event occurred outside in El Niño. may be related to the position of the cente of the snomaly. Every significan El Niño event since 1985 has been accompanied by a significant SST anomaly situated of the east coast of Australia, well soulh of the GBR (see hindcast SST anomaly products on http:/coralreclwatchnoita.gov/satellite/). The 2002 bleaching event had a smaller, less inlense anomaly than that of 1998, but it was situnted in the Coral Sea directly of the central GBR. It is this proximity that allowed it to have a tar greater influence over local GBR conditions and hence the more significant levels of bleaching observed during 2002. [Liu el ilk., 2003]

Clearly short- and long-term effects are intertwined. There is a need to monitor local conditions in order to forecast coral blenching events and also to expect some modulation of the frequency and intensity of bleaching events due to the changing cirmate.

\section{Spatial Variability of SST During a Bleaching Event}

Duting a bleaching event, spatial patterns of SST are quite complex and have a scale of humdreds to lens of housands of meters. Plate $I$ is is taken from Skirving and Guinotte $[2001\}$ and is an SST image of the southern GBR during the 1998 bleaching event. It clearly shows the high complexity that existed in the spatial patterns of SST doring this event. Skirving and Gumote [2001] also point ont that ihis bleaching event (like most others around the world) was characterized by bright sunny skjes and very low winds. This is generally accepted as a crucial part of the formula for a thermally induced mass coral blenching cvent.

Onc problem with this is that the spatial scales of bright sunny skies (i.e., no cloud) are much larger than the observed variability in SST. This means that we need to look for local 


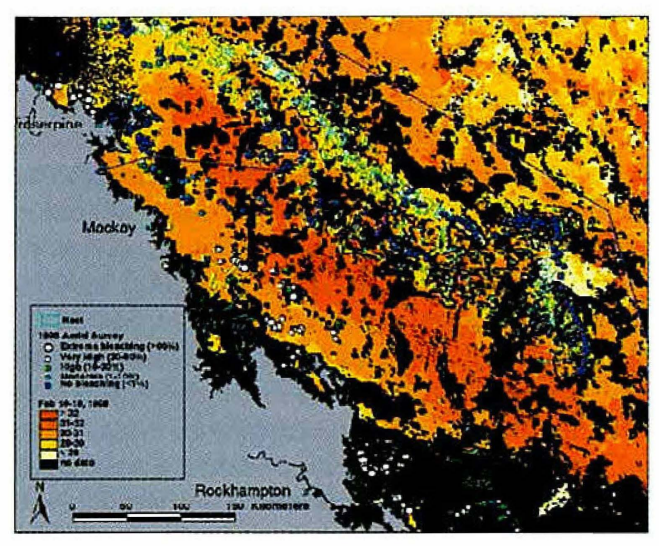

1a

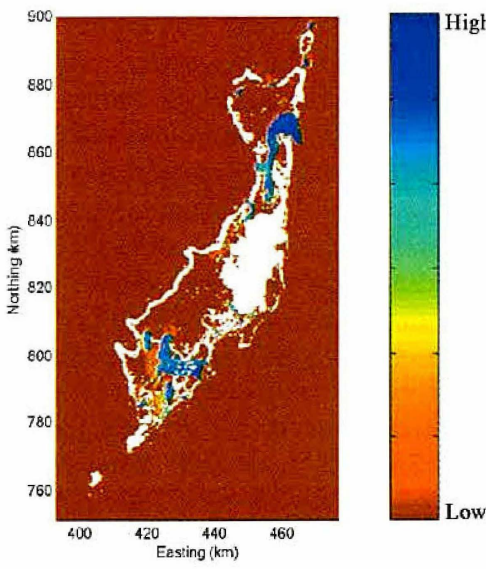

$1 b$

Plate 1. (a) Average SST for 16-18 ${ }^{\text {th }}$ February for the Southern GBR region. Reefs and bleaching are also depicted. (from Skirving and Guinotte, 2001). (b) Map of thermal capacitance for Palau, ranging from low (red) to high (blue). (modified from Heron and Skirving, 2004) 
colditions which intervene in the crusal link between insolation and sea surface temperature and which inpose the observed spatial variability in the SST. It has been suggested that, in the absence of wind, hydrodynamic mixing is the only mechanism that could create such a consplex SST pattern [Skirving and Guinotte, 2001; Skirving, 2004; Skirving et al., 2004].

Solar eлcrgy is absorbed mainly within the top few meters of the water coiumn and, without any vertical mixing, lends to form a stable stratified layer with the warmer water at the top. If theie is no vertical mixing then the warn surface layer has the potential to cause coral bleaching. If there is vertical mixing then the temperature of the surface water is reduced and approaches the average temperature of the water column, and the SST condition for bleaching is less likely to occur.

There are four different mechanisuns that can vertically mix the water colunn: wind, low frequency currents [e.g., East Australian Current, Gulf Stream, etc], high frequency currents (e.g., tides) and swell waves.

The effect of winds on the sea surface is to cause surface stress which in turn can form surface gravity waves and also drive surface currents. To a fairly good approximation, low almplitude surface gravity waves are linear and do not lose energy as they propagate. As the wind becomes stronger and the wave heights increase the non-linear effects grow and energy is lost at the surface in micro-breakers, whitecaps and breaking waves. Energy which is lost from the waves ends up as turbulent mixing in the water column. There is little research on the effects of low wind speeds on coral bleaching conditions, and in particular on the effects of current shear caused near the surface by these winds.

Low- and higly-frequency currents on continental shelves experience frictionaj stress at the sea floor, and this is projected through the vcrtical colum as turbulent kinetic energy and vertical mixing. There are also inherent instabilities in water flow when the current speeds are high. Since the water at the surface is warmer than the water below it, complete mixing in the vertical will result in a cooling at the surface and a warming at deplb. Further to this, deeper locations would experience a larger reduction in the surface temperature by this mechunisın. Therefore, during a blenching event, there is a relationsilip between the patterns of SST and a combination of the depth of water and strength of the currents [Skirving et al., 2004; Heron and Skirving, 2004].

Swell can affect the local vertical mixing in the water column. Swell is defined as long wavelength gravity waves generated outside of the local atea. Thus, it is quite possible to have sivell when there are no local wind waves. The most oramatic effect of swell is on the exposed side of a reef where swell breaks. Solme of the energy is transferred into an overflowing bore which carries water onto the reef Clat, but most of it is dispersed into turbulence at the reef front. There is a zone at the outer edge of a reef on the exposed side where significant vertical mixing can occur even in the absence of winds and currenis,

\section{The Physics of Vertical Mixing}

During the daylight hours there is generally a net flow of heat into the ocean. The major part of this flux is in the form of electromagnetic radiation which is absotbed in the upper layers of the ocean. The resulting warm layer may then be mixed down by dynamical processes driven by currents and waves. The outflow of heat through the sea surface dominates at nigh. The combination of these fluxes gives a net diumal variation whose longterm mean sets the climatological mean for the sea suffacc temperature. 


\section{Insolation}

The solar radiation spectrum at the bottom of the atmosphere peaks in the visible range of wavelengths and has absorption lines and bands due to the composition of the atmosphere. Figure 1 (upper panel) shows typical spectra for the incident solar radiation at the top of the atmosphere and at the sea surface. This a conceptual sketch and for accurate calculations we need to use detailed estimates which take into account the variations in the solar constant and the latitude of the reef. The atmospheric model for absorption in this case changes the total energy from $1353 \mathrm{~W} / \mathrm{m}^{2}$ at the top of the atmosphere [Thekackara and Drummond, 1971] to $933 \mathrm{~W} / \mathrm{m}^{2}$ at the sea surface. To calculate the atmospheric absorption for a particular site an atmospheric model, such as MODTRAN [Bemstein et al., 1996], can be used. The main control on the energy arriving at the sea strface is exerted by the aerosol and witer vapor content of the atmosphere. Therefore, the type of air mass above a coral reef will have considerable influence over the amount of surface solar radiation. A clear sky and low aerosol content, which occur in regions such as the Red Sea and parts of the GBR, will provide maximum insolation. This is evident in the extreme SSTs often recorded in parts of these regions.

Conversely, regions that experience dust storms, high humidity and cloudy conditions will experience lower amounts of insolation, with the same sun angles, resulting in lower SSTs.
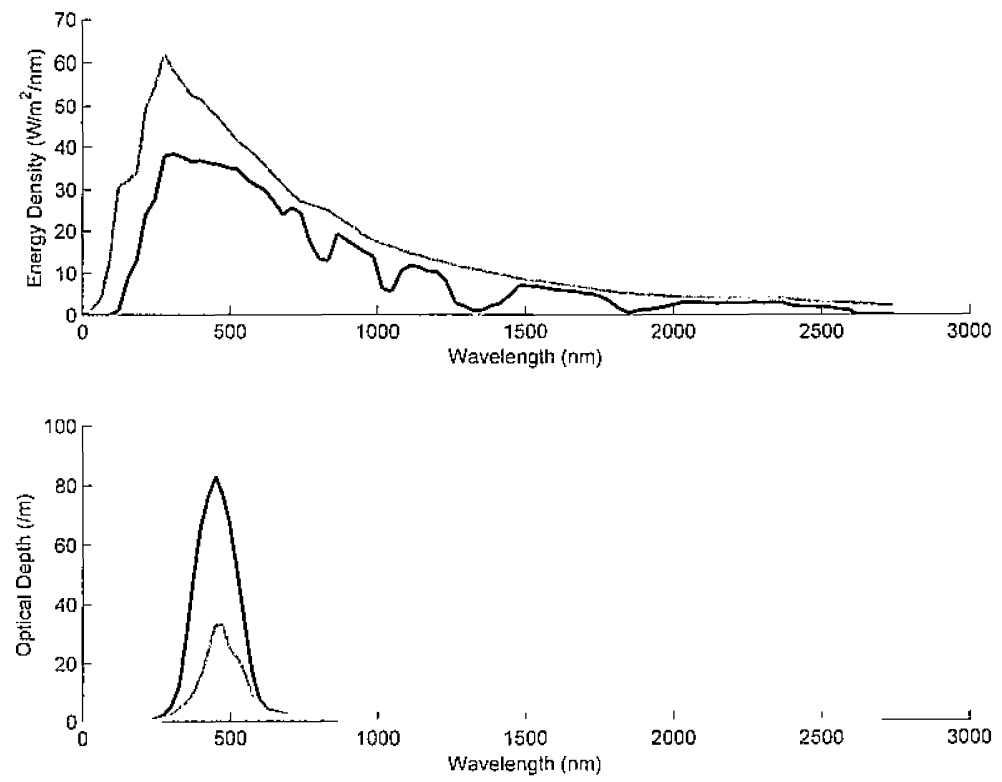

Figure 1. (Upper panel) Stylized graph of solar energy density at the top of the atmosphere (dark grey) and at the sea surface (biack). (Lower panel) Stylized optical depth for case I water (black), case II water (dark grey) and case III water (light grey). 


\section{Absorption}

For a siugle radiation wavelength and homogeneous water the amount of radiant energy absorbed, $\Delta I$, in an interval of depth, $\Delta \bar{z}$, is assumed to depend on the amount incident on that interval. This can be written as

$$
\Delta I=-\alpha I \Delta z
$$

where $\alpha$ is an absorption coefficient equal to the inverse of the optical depth, $I$ is the incident energy. and $z$ is the depth. Equation (1) leads directly to the expression for the radiant energy, $l(z)$, at deptl $=$ in the water column in terms of the energy $I_{0}$ incident at the surface.

$$
I(z)=I_{0} \exp (-\alpha z)
$$

Equations (1) and (2) work for a single absorbing constituent in the water, and for an absoiption coefficient which has no variation with deplh. This is often not the case. Figure 1 (lower panel) shows how the optical depth $(1 / \alpha)$ varies with wavelength for three different types of water (case I - extremely pure ocean water, case II - turbid cropical-subtiopical water, case III - mid-latitude water [Stewart, 2005; Jerlov, 1976]). This scluematic illustrates the point that radiation in the visible band penetrates much fusther into the water than infra-red radiation which is absorbed very close to the surtace, even in the clearest of case I waters. Under these conditions the absorption has to be calculated by summation across all wavelengths for aach layer of water. To express this we recognize that the iucident radiation varies with wavelengll as slown in the upper panel of Figure 1

$$
l_{0}=\sum_{j} E(\lambda) \Delta \lambda
$$

where $E(\lambda)$ is the energy density at the sen surface. Because each wavelength has its own value of optical depth $(I / \alpha)$ we have to calculate the attenuation through the water column to depth ; for each wavelength, and then add them up to find the total remaining energy at that deptir.

$$
I(z)=\sum_{i} \sum_{i} E(\lambda) \exp (-\alpha z) \Delta \lambda \Delta z
$$

This is the value plotted in Figure 2 for the insolation and optical depths shown in Figure 1. Note that the curves shown in Figure 2 ate not exponential; they are the sum of exponentials with differing optical depths. The most striking feature of Figute 2 is that $90 \%$ of the insolation energy is absorbed above $2.32 \mathrm{~m}, 0.81 \mathrm{~m}$ and $0.35 \mathrm{~m}$ for case $\mathrm{I}$, case II and case III water respectively. This is juxtaposed with the fact ihall case ] water has an optical dejsth of up to $80 \mathrm{~m}$ at about $450 \mathrm{~nm}$.

For the purpose of discussing the henting effect of insolation energy in the water colunn, the henting effect is restricted to the top (approx) $1 \mathrm{~m}$ in case II water. This clearly demonstrates the importance of vertical mixing if this heat energy is to be removed from the surface lnyer:

Equation (4) assumes titat the opticai depth of the water is constant though the water column. If there is any layering of the biomass or sediments then the optical depth $(J / \alpha)$ may vary with depth and this could be put into a modificd form of Equation (4). 


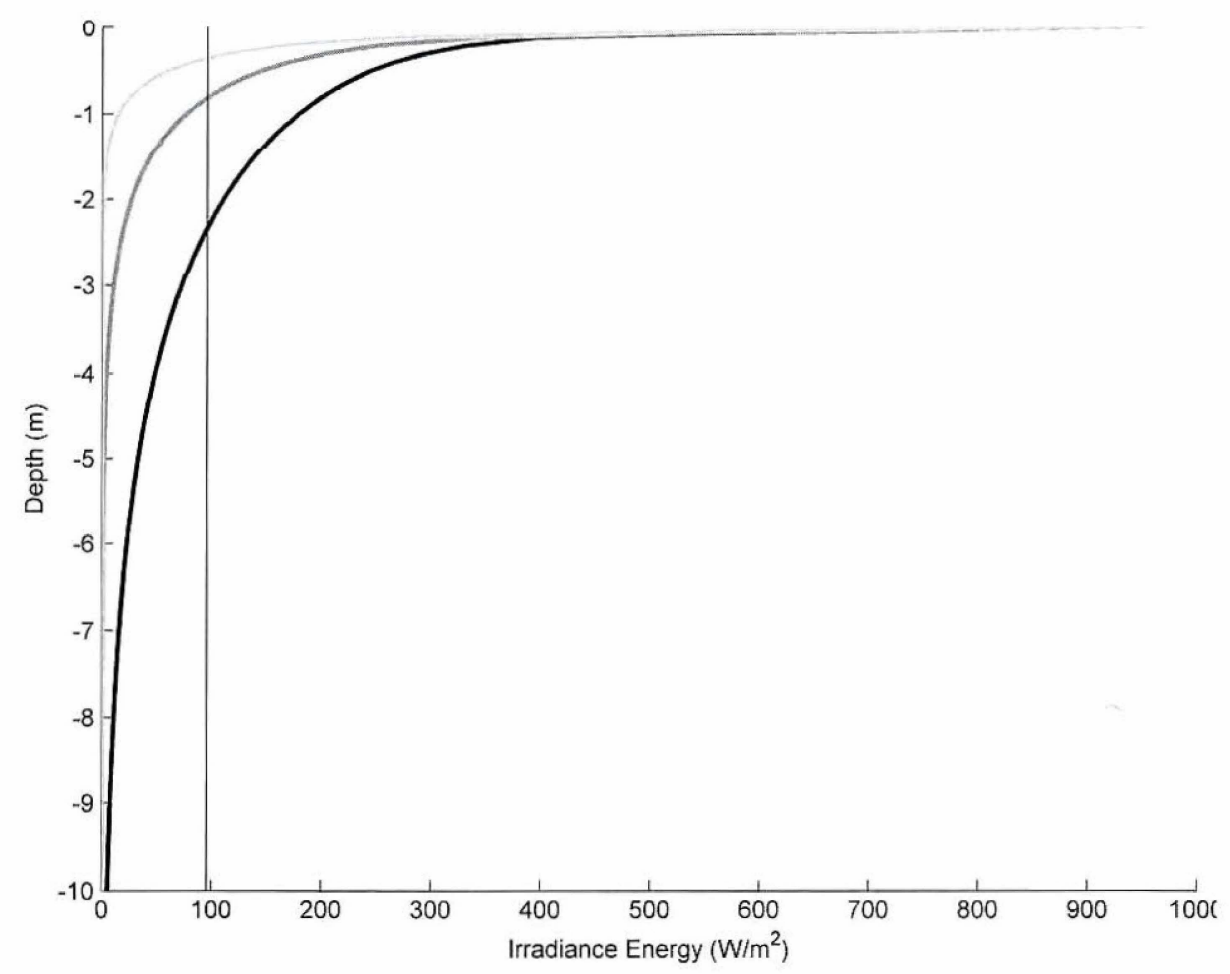

Figure 2. Total radiation energy, integrated over all wavelengths, decreases with depth for the case I water (black), case II water (dark grey) and case III water (light grey) data shown in Figure 1. The thin vertical line can be used to find the depths at which the energy density in the radiation has fallen to $10 \%$ of the value at the surface.

\section{Dynamical mixing by currents}

Ocean currents have a tendency to induce mixing under most conditions. In shallow water, where we are likely to encounter coral reefs, we can expect a boundary layer shear flow due to friction at the bottom of the water column. This is the basic response to tides and geostrophic forcing, to which we can superpose the effects of wind stress at the surface, stratification and wave-induced mixing. Note that the only concept of laminar flow is in the viscous layer at the bottom, and eddy diffusion prevails throughout the water column.

Mixing due to currents is driven by the vertical shear in the horizontal velocity of the water in the column and is carried out by eddies in the vertical plane. A commonly assumed model for the vertical eddy viscosity, $N_{z}$, is the linear model given by

$$
N_{z}=k u_{*}(h-z)
$$


which leads to the logarithmic bottom-friction layer,

$$
u(z)=\frac{u_{*}}{k} \ln \left(\frac{h-z}{z_{0}}\right),
$$

where $z$ is the distance from the surface (positive downwords), $h$ is the water depth, $z_{0}$ is the thickness of the viscous layer, $t_{t}$ is the friction velocty and $k$ is the vou Karnan constant. The vertical gradient in the honzontal flow has a shearing tendency which induces mixing.

Mixing of the vertical column due to bottom friction is strongest near the bottom where velocity shears are greatest. However with strong currents and shallow water this call impact on the mixing of the upper solar-heated layer. One important thing about this simple theory of mixing in the logntithmic boundary layer is that it gives us a conceptual reference frame for turbulent mixing in the water column when velocity shears are caused by olber phenomena.

One such phenomenon is the formation of a horizontal eddy on the lee side of verticn] obstnictions (reefs, islands, etc.) [see Wolanski et al., 1984]. Such eddies are formed by large horizontal shears between the main flow and the shadow of the structure, wherc the horizontal turbulence scales are favorable (i.e., appropriate Reynotds number). As this mecluanism requires significant currents, it is likely that the botton-friction mixing associated with the currents will be substantial.

\section{Mixing due to wind stress}

Wind at the surface of the sea produces momentum transfer to the water, and hence a wind stress velocity at the surfacc. The velocity at the surfoce is transferred down through the column by eddy diffusion. If we nssume that the verlical eddy viscosity, controlled by the stress at the surface, grows linearly with depth then we have a mahematical form similar to the bottom friction layer witl:

$$
N_{i}^{\prime}=k z i_{*}^{\prime} z
$$

where $z$ is the distance from the water surface (positive downwards), and $u_{*}^{\prime}$ is the stress velocity at the surface.

The actual eddy viscosity in the water column is a combination of $N^{\prime}$ and $N_{*}$, and the velocity profile is a combination of the bottom bounclary layer and the surface boundary layer. This leads to complications in numerical modeling of the currents and various schemes lave been suggested for combining the eddy viscosity terms.

It is clear that the velocity shears induced by wind at the surface of the water have a significast rolc in the vertical mixing of the surface solar heated layer. Bleaching weather suggests little to no wind; in practice, low-speed winds generally exist and need to be considered.

\section{Stratification}

Stratification imposes an impediment to mixing due to the potential energy of the stratification. The Richardson number compares the potential energy (PE) of stratification and 
the turbulent kinetic energy (KE) and provides us with an index to moasure the severity of the sltatification. Under these conditions the turbulent kinetic energy works to crode the stratified layer:

Following the approacl of Simpson and Hunter [1974], de Silva Samarasinghe [1989], and others, we considier the rate of loss of potential energy to be equal to some small fraction per second, $\sigma$, of the tubulent kinetic energy as

$$
\frac{\partial}{\partial t}(P E)=-\sigma(K E)
$$

which can be written as

$$
\frac{\partial}{\partial t}\left\{\int_{i z}^{t} g z(\rho-\bar{\rho}) d z\right\}+\sigma \bar{\rho} \int_{0}^{h} N_{i}\left(\frac{\partial u}{\partial z}\right)^{2} d z=0
$$

per unit area of the water column, where $h$ is the depth of the water column, $g$ is gravitational acceleration. $\rho$ is the density, $\phi$ is the mean water density in the column, $w$ is the horizontal velocity, and $N_{-}$is the vertical eddy viscosity. Simpson and Hunter [1974] found $\sigma=0.0037 \mathrm{~s}^{-1}$ it the Ihis! Sea; Hean $[1985]$ derived a sinilar valuc.

Equations 9 and 10 give us important insights into the stability of the upper layer in the water. When the sun heats the surface layer, the density of that layer is reduced, the potential encrgy (in Equation 9) is increased, and the water column is likely to be inherently stable. When PE dominates there is a high risk of coral bleaching. If the KE term in Equations 9 and 10 is large then muxing is enhanced and the density gradient is eroded. When KE donitutes the solar hented water is mixed with deeper water and the risk of coral bleaching is reduced.

An elementary model for predicting the conditions for coral bleaching can use observed or estimated currents $(u)$ and local water deptin $(h)$ for gauging the relative importance of the etiergy terms. This approach is to carry out a calibiation (using previous data) of current speed against vertical mixing (or even against the mitigation of bleaching).

If there is wind stress driving currents in the warm surface layer then there is likely to be an enhanced current sheal at the boltom boundary of the stratification which can assist mixing.

Another form of stratification is the thin surface layer which is evaporatively cooled by waler vapor (latent heat) flux from the ocean to the atmosphere. This is a thin layer of the orter of millimeters, with a regencration the constant of scveral seconds if it is destroycd. for example, by a micro-breaker [Mobasheri, 1995]. This layer is unsiable in the waler colun m and promotes mixing. When we put this micro-layer mixing in the conticxt of solar insolation on the order of a meter depth below the surface it is quickly lost in the scales of encrgy transfer and penetration deptly. A more signilicant effect of the "skin layer" is that it is this layer whicl provides the infrared radiation used by satellite radiomelers to measure the surace temperature. The skin hyer reduces the brighness temperature by up to hall a (legree-Celsius (and perhaps more in tropical waters). This is not a random error, but is a variable offset in the measured temperature which depends on the nature of the shin layer.

The skin layer has little impact on coral bleaching because it is so thin that it does not coutain much heat entrgy. 
Mixing due to wave breaking

In the open ocean, most of the wave energy is constrved and not lost to mixing processes. It is only when the waves becone non-linear that they fose energy to turbulence. It is the process of wave breaking that dominates the transfer of wave energy to mixing. At ree fronts the transfer is almost complete wilh only a remmant of wave energy being rellected back to the ocean, some of it transferring to a forwird bore in the breaking wave, and a sjunificant fraction going into turbulence at the breaker location. For a propagating surface gravity wave most of the energy is in the upper part of the water column. This is illustrated in Figure 3 where we stow the depth profile of the horizontal surge velocity for a wave with $1 \mathrm{~m}$ amplitude (mean to crest) and $6 \mathrm{~s}$ period. This is a typical oceanic wind wave and the graph shows how the velocity decreases rapidly with depth. If there is any non-linearity or breaking then the associated energy becones available for mixing.

The kinetic energy density for a wave with amplitude, $a$, angular frequency, $\omega$ and wavenumber, $k$ is given by

$$
K E(z)=\frac{1}{2} \rho\left(u^{2}+w^{2}\right)
$$

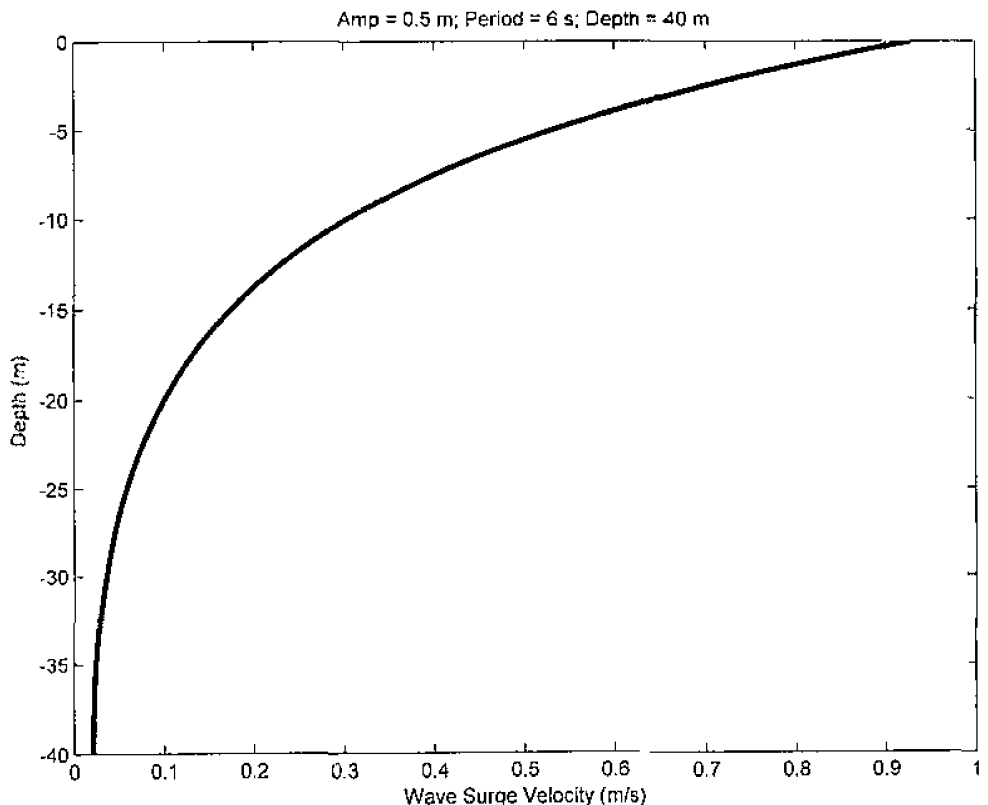

Figure 3. Horizontal surge velocily versus depth for a lypicil wind wave. Most of the wive cnergy is in the top few meters. The vertical surge velocity profile follows the same curve near the surface but depants and goes to zero at the bottom of the water columb, set to $40 \mathrm{~m}$ here. 
where $u$, and $w$ are the instantaneous horizontal and vertical deptl-dependent particle velocities:

$$
\begin{aligned}
& u^{2}=\frac{\pi a^{2} g^{2} k^{2}}{\omega^{2}} \frac{\cosh ^{2}(k(h-z))}{\cosh ^{2}(k h)} \\
& w^{2}=\frac{\pi a^{2} g^{2} k^{2}}{\omega^{2}} \frac{\sinh ^{2}(k(h-z))}{\cosh ^{2}(k h)}
\end{aligned}
$$

where $\rho$ is the density, $g$ is gravitational acceleration, $h$ is the depth of the water column and $z$ is the (positive-downward) distance below the sea surface.

This wave energy is genernily not avaitable for mixing on shelf waters. However, when a wave encounters a reef front it loses most of its energy and provides a dominant mixing effect for the solar heated layer near the surface. This effect is so dominant that it is difficult to think there would be coral bleaching on the weather side of a reef except in very flat-calm conditions. Waves breaking on the reef front also send pulses of water forward across the reef flat. This pulsing bore is also well-mixed and we would expect mitigation of bleaching on the parts of the reef flat that are flushed with this water.

The physical processes of wave breaking on the reef front and tise subsequent puising of water across the reef flat have a strong mitigating effect on coral bleacling.

\section{Hydrodynamic Modeling for a Bleaching Event}

The physicai mechanisms that can influence bleaching are deterninistic and, as such, can be modeled to predict the spatial variations in thermal stress. Bleaching weather conditions suggest maximum insolation and no signiffant wind-induced mixing. The inclusion of a parameter for swell is yet to be done. The effect of swell on mixing depends on the swell direction and the bathymetry of the reef and its surrounds. Swell waves are very effective mixers where they exist and call nix the water when they impinge on a reef. However, they are not capable of cooling an entire reef and will not be available for every reet. Swell may therefore contribute to the variability of coral bleacting on local scales; however, it is yel to be included in the hydrodynamic model presented here.

This leaves currents as the only mechanism which the model considers for altering spatial patterns of SST. The vertical temperature profile is determined by surface heat flux, dominated by solar radjation. Currents then mix this vertical profile via bottom friction and turbulent kinetic energy. The spatial pattern of mixing then modulates the vertical temperature prolites to create patterns of low to high SST during a bleaching event. To date, coral bleaching has occurred in regions of ligh SST, will the regions of cool water remaining refatively stress fiee. The case study described in the next section illustrates the success of linking hydrodynamic modeling of currents to the modulation of coral bleaching.

Case study - Palau heat stress model

During the latter half of 1998, Palau experienced unprecedented bleaching that resulted in significant mortality and the loss of significant proportions of one of the few renaining pristine coral reefs in the world [Wilkinson, 2002]. Prior to and since 1998, little to 
no coral bleaching has been observed. Figure 4 is a plot of accumulated heat stress at Palau as measured by the NOAA Conal Reef Watch DHW satellite product. A DHW value of 4 or more indicates significant bleaching [Lit et al., 2003; Skirving et al., 2006]. Note the DHW = 4 line in Figure 4; the 1998 accumulated stiess easily surpassed that mark and is the only year to have done so since 1985 . While the DHW product provides a largescale description of coral bleaching events, it does not describe the smaller-scale variations of thermal stress. An understanding of these variations will lead to improved management.

The Nature Conservancy and the Palau Government joined forces to design and implement a Protected Areas Network (PAN) for Palau's coral reef ecosystem. They recognized bleaching as one of the major future threats to the Palau coral reef ecosystem. However, with only one poorly documented bleaching event, it is hard to understand the response of this ecosystem to coral bleaching and then build resilience to such events into the PAN.

At the same time, NOAA and the Australian lnstinute of Marine Science (AIMS) were collaborating on the development of iydrodynamic models to predict heat stress during a bleaching event. In 2003, it was decided to combine these efforts and for NOAA and AIMS to produce a heat stress model for Palau for use in the PAN.

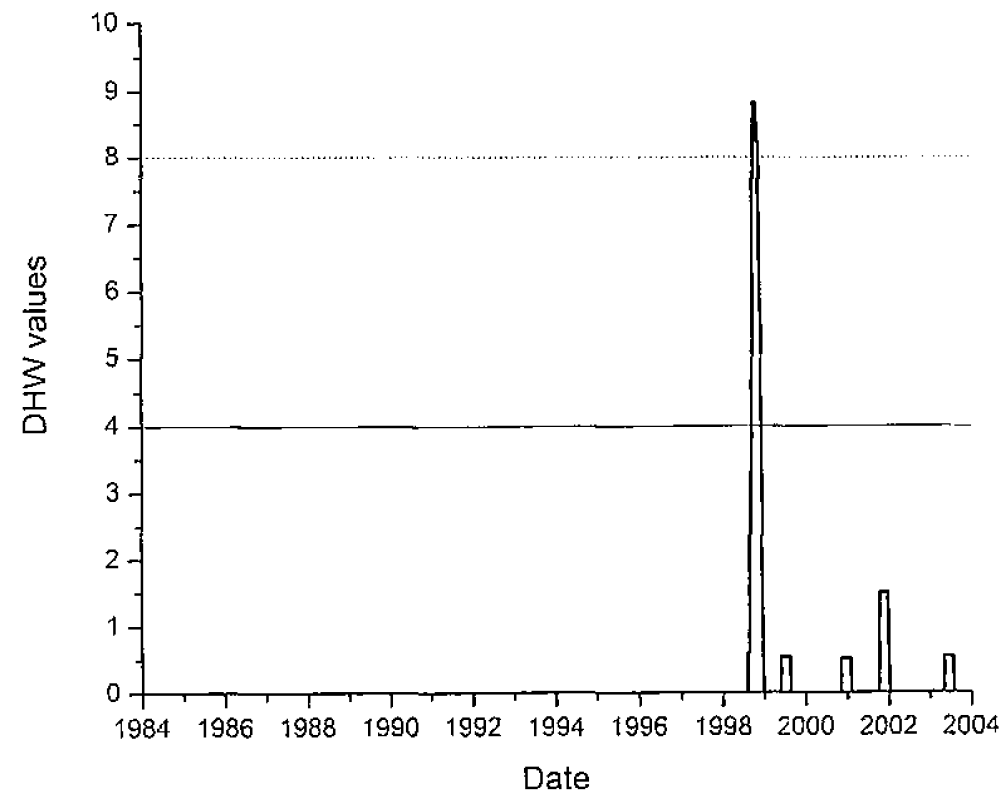

Figure 4. Accumulated thermal coral stress at Palau based on the Degree Heating Week product for the period 1985 to 2004. 
For the model to be constructed, NOAA and AIMS needed [Skirving et al., 2005]:

1) The Palau bathymetry: Due to a lack of available data, NOAA arerived the bathymetry from a combination of Landsat data and balbymetric transects laken with a depth sounder from a small boat. This produced a chatr with 256.5 meter horizontal resoltttion and an rms error of approximately $I$ meter verlically.

2) Low frequency currents: The Naval Researcl Laboratory [NRL] Layered Ocean Model (NLOM) and NOAA's Occan Surface Cuirent Analyses - Real time (OSCAR) were used to derive the seasonal low frequency currents around Palan.

3) High frequency currents: A combination of tide gnuge data collected in and around Palau and a global tidal model was used to derive a model that could accurately predict the tides. The bathymetry and the tidal model were then used with the Princeton Ocean Model (POM) to build a model of tidally induced currents in and around Palatt. Field data collected over a period of 5 months were used to calibrate and validate the output of this model.

4) Vertical temperiture proftie: This was derived by modeling a patch of water with a homogeneous temperature and ipplying a diurnal cycle of solar radiation and a constant, low wind of $2.6 \mathrm{~m} / \mathrm{s}$ for a period of two weeks.

Simpson and Huster [1974] provide the parameterization that was used to distinguish between strotified and svell-mixed water by combining the cureuts with the bathymetric dala. This information was then used in conjunction with the vertical temperature prolile to determine the likely spatial distribution of sea surface temperature. To account for advection and tidal variation, while providing a static image for use in the PAN, the surface cooling due to mixing was accunulated over one tidal cycle (1wo spring-neap cycles). This accumulation parallels the DHW approach used by NOAA/CRW, with units of semperature-time

This model is betler described as a measure of thermal capacitance than as accumulated cooling. Thermal capncitance is the ratio of heat absorbed to the resultant temperature rise. Arests of low themal capacitance will cxhibit a larger increase in temperature for a given amount of heat input than areas of high themal capacitance. Regions with complete verical mixing (greater accumulated cooling) have high thermal capacitance, while stratified regions (lesser or no accumukted cooling) have low themal capacitance.

The result of this is that the well-mixed regions in the Palat model represent regions of mild thermal cimmatology (i.e., less temperature varintion and hence less thermal stress), wherens the stratilied regions represent those areas that will expericnce the most extreme temperature range (i.e., greater themal stress). Plate $1 \mathrm{~b}$ is a thermal capacitance nap derived from the Palau model; the blue regions have ligh capacitance (well-mixed, mild chmote), white the red regions hive low capaciance (stratified, varabte climate).

A chart of this type can be extremely useful when designing a PAN. In general, most PANs are currently designed so as 10 provide protection to "representative bioregions". This means that as much as possible, every type of biotegion within the ecosystem of interest should be equally represented willin the PAN. However, an ecosystcm is not only matde up of different spccies. It is also important to recognize that an ecosystem is made up of organisins that have thigue plyssotogical characteristics within each species. It is adaphation to the local climate (mild or variable) that will define these physiological characteristics.

When designing a PAN, it is relatively straight forward to map biorcgions on the basis of species composition; however, the unique physiological properties within each species arc not represented within these tcchuiques. These physiological clancteristics are likely 
grouped into areas that minic the relative thermal capacitance through the region. As such, even without knowledge of the individual characteristics, it is possible to incorporate the spatial variation of physiology by means of the thermal capacitance.

When considering the ecosystem response to an individual thermal stress (blenching) event, it is the regions of high thermal capacitance which will moderate the temperature rise, thereby experiencing lesser thermal stress. For this reason, high-capacitance areas should be selected for protection. It is injportant to note, however, that during extreme thermal stress events (sucl as was seen in Palau in 1998) cven these areas may experience blcaching conditions.

When considering the sustainability of the ecosystem with respect to long-term climate change, it is the low thermal capacilance regions which should be protected. Lowcapacitance regions experience variable climates exposing organisms to extreme temperatures and, thus, frequent periods of thermal stress. This exposure may lead to increased resilience to rising temperatures, via physiological adaptation, and aid their survival as climate change occurs. Representing equal proportions of high and low thermal capaciance areas is necessary and ideal for the short- and long-term protection of coral reefs.

\section{Conclusion}

Hydrodynamic modeling can provide us with a relatively accurate glimpse of what future stress events may hold for corals. However, for the full potential of the model to be realized and employed in management, additional work is required, Advancements in coral physiology to determine the response of organisms to thermal stress, including issues of acclimation and adaptation, will improve managenent during the existing climate regime. In addition to these, the inclusion of improved clmate nodels (e.g., in spatial resolution and accuracy) would allow more accurate predictions of luture blexching events.

A careful examination of the facts surrounding the physical conditions during thermallyinduced mass coral bleaching events teads to a few surprising conclusions:

1) Mass coral bleaching is a weather event and is nol necessiriby linked will climate.

2) In gemeral, the vast majority of coral reefs around the world are not predisposed to bleacling during an ENSO.

3) Twice as many of the world's reefs bleached during the 1998-99 La Nifia than during 1he 1997-98 El Niño.

4) Bleaching weather is characterized by cloudless (sumny) skies, low to no wind and low currents.

5) $90 \%$ of the sun's energy is absorbed in about the top 2 meter's of the water column.

6) The SST patterns during a bleaching event are dominated by spatial vartations in vertical mixing.

7) The hydrodynamic processes that cause mixing and hence create nost of the SST patterns daring a bjeaching evest are largely predictable.

In general, this means that atthough the timing of a coral bleaching event is unknown and cannot be predicted with current technology, the relative palterns of SST during the next blenching event can be predicted using current techniques for bydrodynanic modeling. Hydrodynanic modeling, when combined with an inproved knowledge of conal physiology, can go a long way to heiping us understand the exact nature of mass coral bleaching, allowing for improved monitoring and predictions. 


\section{Implications for Management}

Although the vertical profile of temperature can change from event to event, the mixing parameters change very little as the tidai and low frequency currents are cyclic and thus effectively predictable for any specific location. These parameters can be used to identify, using hydrodynamic inodeling tcchniques, the variation of thernal capaciance across the region of intercst. The result is that the SST pattern during a severe bleaching event is effectively static from one blcaching event to another, with the magnitude of temperature related to the input heat. Identification of these patterns allows a higher degree of nuanagement of coral reefs prior to and during the onset of thermal stress events.

\section{References}

Arzayus, L. F. and W. J. Skirviug, The correlation between ENSO and coral blcaching events. $10^{\text {th }}$ Intemational Cortl Reef Symposimm, Okinawil, Japan, 2004.

Berkelmans, R., Time-integrated thermal bleaching thresholds of reefs and their variation on the Great Barrier Reef, Mar; Ecol. Prog. Sor, 229, 73-82, 2002.

Berkelmans, R., G. De'ath, S. Kinimmonth, and W. Skirving, Conal bleaching on the Great Barrier Reef: Correlation with sea surface temperature, a handle on 'patchiness' and compurison of the 1998 and 2002 events. Coral Reefs, 23, 74-83, 2004.

Bernstein, L. S., A. Berk, and P. K. Acharya. Very narrow band model calculations of atmospheric fluxes and cooling rates using the MODTRAN code, J. Ammos. Sci., 53. 2887-2904, 1996.

Bird, J. C., C. R. Steinberg, T. A. Hardy, L. B. Mason, R. M. Brinkman, and L. Bode, Modeling Sub-Reef Scate Thermodynamics al Scon Reef, Western Ausiralia to Predict Corn Bleaching. 10th International Coral Reuf Symposimm, Okinawa, Japan, 2004.

de Silva Samarasinghe, J. R., Tratsient salt-wedges in a tidal gulf: A criterion for their forma(ion. Estuarine, Coastal and Shelf Science, 28, 129-148, 1989.

Demis, G. D. and R. I. Wickiund, The relationship between environmental factors and coral bleaching at Lee Stocking Island, Babamas in 1990. In: Case Histories for the Colloquinm and Fortan on Global Aspects of Coral Recfs: Heallh, Hazards and History, F15-1F21, 1993.

Downs, C. A., J. E. Fauth. J. C. Hialis, P. Dustan, J. Bentiss, and C. M. Woodley, Oxidative stress and seasonal coral bleaching. Free Radical Biology and Medicine, 33, 533-543, 2002 .

Droltet, J. H., M. Fatcon, S. Maritorena. and P. M. V. Martin, A survey of enviromental physico-chemical parameters during a minor coral mass blcaching event in Tahit in 1993. Aust. J. Mas: Freshw Res., 45, 1149-1156. 1994.

Glynn, P. W. Conal reef blenching: ecological perspectives. Coral Recfs, 12, 1-17, 1993.

Hearn, C. J. On the value of the mixing efficiency in the Simpson-Hunter $\mathrm{h} / \mathrm{u}^{3}$ criterion. Dewtsche Hydrographisches Zeitschrift, 38(H.3), 133-145, 1985.

Heron, S. F. and W. J. Skirving, Satellite batliymetry use in numerical models of ocean thermal stress. La Revista Gavana, 68(2), 284-288, 2004.

Hoegh-Guldberg, $O$., Climate change, coral bleaching and the future of the world's coral reefs. Mat Freshw'ater Res., 50, 839-866, 1999.

Jerlov. N. G., Marine Optics, Elsertes; Amsterdnm, pr. 232, 1976.

Jones, R. J., O. Hoegh-Guldberg, A. W. D. Larcum, and U. Schreiber. Temperature-induced beaching of corals begins with impairment of the $\mathrm{CO}_{2}$ fixation mechanism in zooxanthellae. Plant, Cell and En:, 21,1219-1230, 1998

Liu, G. A. E. Strong, and W. J. Skirving, Remote sensing of sea surface temperatures during 2002 Great Burrier Reef coral bleaching. EOS, S4, 137-144, 2003. 
McField, M. D., Coral response during and after mass bleaching in Belizc. Bull. Mar Sci, 64, $155-172,1999$.

Mobasheri, M. R., Heat transfer in the upper layer of the ocean with application to the correction of satellite sea surface temperature. Ph.D. thesis, Jannes Cook University, Townsville. Australia, pp. 182, 1995.

Simpson, J. H. and J. R. Hunter, Fronts in the Irish Sea. Nature, 250, 404-406, 1974.

Skirving, W. J., The Hydrodynamics of a Coral Bleaching Event: The role of satellite and CREWS measurements. In: Hendee, J. C. (Ed.) The effects of combined sea temperature, light, and carbon dioxide on coral bleaching, sentement, and growth and NOAA Research Special Report, pp. 33-34, 2004.

Skirving, W. J., and J. Guinotte, The sea surface temperature story on the Great Barrier Reef during the coral bleaching event of 1998. In: Wolanski, E. (Ed) Oceanographic process of Coral Reefs: Physical and Biological Links in the Great Barrier Reef. CRC Press, Boca Raton, Florida, pp. 376, 2001

Skirving, W. J., S. F. Heron, C. R. Steinberg, A. E. Strong, C. McLean, M. L. Heron, S. M. Choukroun, L. F. Arzayus, and A. G. Bauman, "Palau Modeling Final Report" National Oceanic and Amospheric Administration and Australian Instinte of Marine Science, pp. 46, 2005.

Skirving, W. J., C. R. Steinberg, and S. F. Heron, The hydrodynanics of a coral bleacling event. ASLO/TOS Ocean Research 2004 Conference, Honolulu, Hawaii, 2004.

Skirving, W. J., A. E. Strong, G. Liu, C. Liu, F. Arzayus, J. Sapper, and E. Bayler, Extreme events and perturbations of coastal ecosystems: Sea surface temperature change and coral bleaching. Chapter 2 in Remote Sensing of Aquatic Coastal Ecosystem Processes, Richardson, L. L. and E. F. LeDrew (Co-Eds), Klower publishers, 2006.

Stewart, R. H., Introduction to Physical Oceanography, Texas A \& $M$ University, College Station, Texas U.S.A., pp. 354, 2005.

Thekaekara, M. P., A. J. Drummond, Standard values for the solar constant and its spectral components. Nature Phys. Sci, 229, 6-9, 1971.

Wilkinson, C. R., Status of Coral Reefs of the World: 1998. Global Coral Reef Monitoring Network and Australion Itstitute of Marine Science, Tounswille, Australia, pp. 184, 1998.

Wilkinson, C. R., Status of Coral Reefs of the World: 2000: Global Coml Reef Monitoring Network and Australian Institute of Marine Science, Townsville, Atrstratia, pp. 363, 2000.

Wilkinson, C. R. Status of Coral Reefs of the World: 2002. Global Coral Recf Monitoring Network and Australian Institute of Marine Science, Townswille, Australia, pp. 378, 2002.

Winter, A., R. S. Appeldoorn, A. Bruckner, E. H. Williams, and C. Goenaga, Sea surface temperatures and coral ref bleaching off La Parguera, Puerto Rico (northeastern Caribbean Sea). Coral Reefs, 17, 377-382, 1998.

Wolanski, E., J. Imberger, and M. L. I-Icron, Island wakes in shallow coastal waters. J. Geophys. Res., 89, 10555-10569, 1984 